\title{
ALGO PARA ALÉM DE TIRAR DA RUA: O ENSINO DO ESPORTE EM PROJETO SOCIOEDUCATIVO
}

\author{
MS. LEOPOLDO KATSUKI HIRAMA \\ Mestre em Ciências do Esporte pela Faculdade de Educação \\ Física da Universidade Estadual de Campinas FEF-UNICAMP \\ Professor do Centro de Formação de Professores da Universidade Federal do \\ Recôncavo da Bahia- CFP/UFRB (Amargosa - Bahia - Brasil) \\ Email: leopoldohirama@yahoo.com.br
}

\section{DR. PAULO CÉSAR MONTAGNER \\ Doutor em Educação Física na Faculdade de Educação Física da \\ Universidade Estadual de Campinas FEF-UNICAMP}

Professor da Faculdade de Educação Física (FEF) da Universidade Estadual de Campinas (UNICAMP)

(Campinas - São Paulo - Brasil)

Email pcesarm@fef.unicamp.br

\begin{abstract}
RESUMO
O presente artigo está vinculado a uma pesquisa de tipo etnográfico e de reconstrução de memórias orientado pela história oral, e teve como objetivo principal apresentar características relevantes de um projeto socioeducativo na comunidade de Heliópolis, na cidade de São Paulo, procurando compreender as transformações vividas por adolescentes em seu cotidiano, relacionando as possíveis contribuições para a estruturação de ações que possuam o esporte como eixo norteador. Destacaram-se como resultados mais significativos a relação professor-aluno, o sentimento de pertencimento e a continuidade no aprendizado. Concluiu-se o estudo indicando a importância de tratamento pedagógico criterioso ao se oferecer esporte como foco de atuação voltada para comunidades populares.
\end{abstract}

PALAVRAS-CHAVE: Esporte; projeto socioeducativo; classes populares; adolescentes. 
Está em franca expansão um novo espaço de atuação do profissional de Educação Física: as Organizações Não-Governamentais (ONGs) que, entre outros eixos, trabalham com o ensino de esporte em projetos socioeducativos voltados, em geral, para classes populares. A origem do termo Organização Não-Governamental está vinculada ao surgimento do Terceiro Setor. Segundo Thompson (2005, p. 45), seu surgimento aconteceu entre as décadas de 1960 e 1970, agindo em oposição ao autoritarismo:

Havia surgido em um contexto de regimes militares, como alternativa ao fechamento do sistema político e seu principal propósito era o de manter espaços de ação cidadã e de defesa de certos valores democráticos.

Também na mesma época surgiram organizações internacionais que buscavam promover projetos de desenvolvimento no Terceiro Mundo, incluindo o Brasil (FERNANDES, 2005). Anteriormente, existiam apenas dois setores, o governo e a sociedade civil, sendo que nesta última estava incluído o mercado. As lutas contra o militarismo e a pressão da produção e do lucro, característica do mercado, destacaram estas organizações civis, contribuindo para a formação do Terceiro Setor.

Segundo Gohn (200l, p. 82), após a Segunda Guerra Mundial surgem as ONGs, que se diversificaram em variados setores de atuação e se identificam como parte do terceiro setor:

As ONGs estão mudando de nome para simplesmente terceiro setor. Para uns trata-se apenas de mais uma forma de exploração da força de trabalho, uma resposta das elites à organização e mobilização sindical e popular dos anos 80, bem assim como parte das estratégias neoliberais para desobrigar o Estado de atuar na área social. Para outros, o terceiro setor é algo realmente novo, pois o Estado não consegue mais penetrar nas microesferas da sociedade. Ele só saberia atuar no nível macro, e as políticas públicas necessitam de mediadores para serem efetivas. Quanto ao poder local, o terceiro setor estaria contribuindo para o desenvolvimento de novas formas de associativismo.

O Brasil vive um fenômeno de crescimento acentuado no número de ONGs (organizações não-governamentais), conhecidas também como fundações privadas e associações sem fins lucrativos, atuantes nas mais diversas áreas, entre elas a educação. Segundo o Instituto Brasileiro de Geografia e Estatística (IBGE, 2004), são ao todo 275.895 instituições desta natureza no país, em levantamento realizado em 2002. O ritmo de crescimento vem aumentando a cada década. Dos anos 70 aos 80 foi de $88 \%$, dos anos 80 aos 90 foi de 124\%, e de 1996 a 2002 o crescimento foi de $157 \%$. 
Aproximando-se da educação física, segundo o IBGE (2004) são 26.894 ONGs que se classificam como atuantes na área de recreação e esporte, o que representa $9.75 \%$ do total, explicitando o significativo espaço de atuação para o profissional da área.

Diante deste quadro, este estudo investigou um projeto socioeducativo executado na comunidade de Heliópolis, São Paulo, que possuía como eixo fundamental de suas ações o ensino do esporte. Objetivaram-se encontrar os significados construídos pelos envolvidos na participação do projeto, as possíveis transformações em suas vidas e as características principais que nortearam as ações vivenciadas. Para tanto, reconstruíram-se as memórias de alunos, lideranças e professores participantes do projeto socieducativo, que foi vivenciado durante três anos. Também as próprias memórias de um dos autores deste texto foram consideradas, aproveitando-se de sua imersão na comunidade, onde morou e participou de todo o processo. As impressões levantadas foram transcritas em sua totalidade, separadas em agrupamentos temáticos, cruzando-se opiniões convergentes e divergentes e, finalmente, seguidas pelas considerações (HIRAMA, 2008). Buscou-se, por fim, colaborar para a reflexão sobre as características consideradas importantes pela pesquisa, na especificidade da intervenção da pedagogia do esporte em projetos sociais destinados a crianças e jovens carentes.

\section{A "FAVELA"' E A PESQUISA}

A comunidade onde se realizou este estudo pertence à zona sul da cidade de São Paulo, e está localizada no bairro do Sacomã. Originou-se a partir de uma desocupação realizada pela prefeitura no bairro de Vila Prudente, no início da década de 70. Desde então, a comunidade tem crescido acentuadamente, sendo considerada a maior do Estado de São Paulo em número de habitantes. Estima-se que vivam ali, atualmente, cerca de 125 mil habitantes. ${ }^{2}$

Diante deste cenário, cada vez mais comum no país, de bolsões de moradias populares, com alta densidade demográfica, de milhares de crianças e jovens com menor acesso a espaços educacionais adequados, a questão norteadora da pesquisa foi: Quais as características fundamentais para um projeto socioeducativo que se propõe a oferecer ensino de esporte para esta população?

I. A denominação "favela" aparece entre aspas, pois geralmente vem carregada de sentido pejorativo, o que não reflete a intenção de sua utilização neste texto. Seu uso é justificado por ser uma palavra bastante conhecida, ocorrendo inclusive em outras produções científicas e pelo fato da comunidade estudada tratar o próprio local onde vivem de "favela do Heliópolis".

2. Informações retiradas do site da UNAS (União dos Núcleos, Associações e Sociedades dos Moradores de Heliópolis e São João Climaco): http://www.unas.org.br, acesso em: 17 ago. 2007. 
A resposta para esta questão foi buscada nas entrevistas com ex-participantes do projeto, procurando identificar as aproximações em suas falas, investigando possíveis concordâncias, reunindo-as em temas para discussão.

Como orientação científica, utilizou-se estudo de caso do tipo etnográfico (André, 1995), que se mostrou eficaz para melhor explorar a imersão de um dos pesquisadores na comunidade, durante os três anos em que morou no bairro e trabalhou no projeto como professor. Como metodologia para a reconstrução das memórias dos envolvidos no projeto, adotou-se a história oral, empregando-se o formato de coleta de depoimentos individuais e rodas de conversa para reconstruir as memórias de quatro grupos diferenciados envolvidos no processo de ensino do esporte:

I. Os próprios jovens integrantes do projeto- foram entrevistados vinte de um total de trinta escolhidos aleatoriamente, atentando-se somente à proporcionalidade entre mulheres e homens, sendo que onze participaram da roda de conversa e nove dos depoimentos individuais,

2. Professores- foram entrevistados três professores individualmente, de um total de sete, escolhidos por serem moradores da comunidade,

3. Liderança da comunidade- uma entrevistada, escolhida por ter sido a principal mediadora comunidade/ONG no processo de implantação do projeto,

4. Grupo de jovens de uma geração mais nova- foram entrevistados, na forma de roda de conversa, oito de cerca de cinqüenta, indicados pelos professores pela maior participação nas ações do projeto.

Como referencial científico para este estudo, adotou-se a etnografia, por se mostrar mais adequada ao panorama do ambiente da pesquisa, permitindo ainda explorar a experiência da convivência do pesquisador na comunidade para o aproveitamento do que Laplantine ( 1988, p. I 50) chama de imersão total:

Assim, a etnografia é antes a experiência de uma imersão total, consistindo em uma verdadeira aculturação invertida, na qual, longe de compreender uma sociedade apenas em suas manifestações "exteriores" (Durkheim), devo interiorizá-la nas significações que os próprios indivíduos atribuem a seus comportamentos.

Geertz ( 1989) afirma também que a descrição etnográfica é microscópica. Defendendo o propósito de um estudo de caso, e utilizando-se do mesmo autor em sua citação à investigação local, esta pesquisa não será da comunidade de Heliópolis, e sim na comunidade e em um recorte específico, do grupo de adolescentes participantes do projeto esportivo entre 2003 e 2005.

Em conjunto ao estudo de caso, definiu-se a utilização da história oral como metodologia para a coleta de dados, que é utilizada por diversas áreas do conhecimento, entre elas a antropologia. 
Através do depoimento oral, exploraram-se as chamadas memórias subterrâneas ou marginais (VON SIMSON, 2003), referentes ao passado de grupos dominados que teriam suas lembranças perdidas, caso não se buscasse reconstruí-las, para, então, fazer parte dos lugares de memória, tradicionalmente ocupados pelas memórias das elites dominantes.

A metodologia mostrou-se adequada para levantar dados sobre as lembranças vividas no projeto social, em especial as mais significativas, pois, segundo Von Simson (2003), a memória depende do esquecimento, sendo impossível reter tudo o que vivemos, permanecendo, desta forma, apenas o que foi marcante e funcional. $O$ processo de memorização é mediado pela capacidade de selecionar o que é significativo, do que não é. Tudo o que se separa como não significativo, se esquece, permanecendo o que se identificou como importante, marcante, que pode ser utilizado futuramente. Desta forma, com a coleta dos depoimentos orais, buscou-se o levantamento dos fatos significativos para os jovens, aqueles que mereceram destaque em suas vidas e que foram selecionados para permanecerem na memória, e também suas motivações para tanto.

Braga (2000) reforça a importância da reconstrução da memória, quando afirma que as lembranças individuais estão compreendidas dentro de uma memória coletiva. Idéias, reflexões, sentimentos atribuídos individualmente são inspirados socialmente, colaborando com a reconstrução do cenário coletivo do projeto socieducativo.

Para este texto, foram elencados os trechos da fala referentes ao tema ensino do esporte no projeto vivenciado 3 . Para a análise, relacionou-se os conteúdos coletados com os referenciais teóricos, e as memórias do pesquisador referentes à época em que esteve imerso na comunidade. As aproximações e distanciamentos entre os dados foram selecionados e analisados, gerando a reflexão sobre o tema.

\section{O AMBIENTE: NOÇÕES DE REALIDADE}

O projeto socioeducativo em questão acontecia em um núcleo comunitário que oferecia diversos serviços à comunidade, por meio da associação de três ONGs e com o apoio da prefeitura do município de São Paulo. O programa esportivo, que possuía o voleibol como eixo principal, era administrado por uma ONG dirigida por ex-atleta da modalidade e financiada por uma grande empresa multinacional.

As aulas iniciaram-se em 200 I , oferecendo 200 vagas. Em 2002 o número foi ampliado para 400 vagas para crianças e jovens entre 7 e I 4 anos. Já neste mesmo

3. Para preservar o anonimato dos entrevistados identificou-se apenas a categoria a que pertence o participante. 
ano, um grupo de 30 adolescentes excedia esta idade limite inicial e reivindicavam sua continuidade no projeto, ao qual foram atendidos. Paralelamente à formação de equipes com características competitivas, visando a continuidade dos estímulos esportivos, estes alunos foram protagonistas em diversas ações junto às crianças mais novas, participando como monitores nas aulas diurnas, auxiliando os professores nas aulas e formando uma equipe de arbitragem que organizava os torneios internos e entre núcleos do projeto em nível estadual.

Tamanho foi o empenho e comprometimento dos jovens com as ações, que passaram a ser referência do projeto, tanto diante das próprias crianças em suas aulas, como para seus moradores como um todo, atuando em diferentes ações comunitárias. Esta posição também foi levada para fora da comunidade, ao atuarem como monitores e árbitros em torneios externos e em outros eventos em que o projeto era convidado, inclusive programas de televisão.

A posição atuante na comunidade, oportunizando diversificadas experiências aos seus componentes, foi o motivo principal por se definir este grupo como o foco da pesquisa que originou este texto.

\section{RESULTADOS: AS VOZES DA COMUNIDADE}

Refletindo sobre as informações levantadas através das vozes da comunidade, chegou-se a três aproximações mais presentes e significativas: profundidade e continuidade no aprendizado do voleibol, o sentimento de pertencimento ao grupo e a relação de proximidade professor e aluno. Outros temas são discutidos no estudo original, no entanto, este texto foca a discussão nas aproximações realizadas sobre as afirmações mais freqüentes sobre os temas.

\section{UM DESEJO DOS JOVENS: APRENDER BEM O VOLEIBOL}

O esporte vem sendo utilizado como "ferramenta" de intervenção em diversos programas sociais. Expressões como "tira as crianças da rua!" ou " ensina a trabalhar em equipe!", são comumente atribuídas a ele. No entanto, qual a forma mais adequada de se oferecer este esporte? Muitos espaços desenvolvem esta "ferramenta" como instrumento de recreação para atrair os jovens. Outros defendem um desenvolvimento mais profundo, alguns até em busca de talentos e campeões.

A participação e o sucesso de atletas nos Jogos Panamericanos do Rio, em julho de 2007, que iniciaram a prática esportiva em ONGs, recebeu atenção da mídia ${ }^{4}$. O primeiro medalhista de ouro brasileiro naquela edição dos Jogos, o atleta

4. Extraído do site www.globo.com/rjtv, na sessão globo comunidade, acesso em 24 de julho de 2007. 
Diogo Silva, do taekwondo, iniciou sua trajetória esportiva em um projeto social. Outro medalhista de ouro, o atleta Edson Isaías da Silva, da canoagem, também começou a praticar a modalidade em uma ONG.

Se, por um lado, determinar objetivos para a busca dos talentos esportivos acarretará em exclusão para a maioria, por outro, incluir a todos na forma de estímulos unicamente recreativos e lúdicos poderá não oferecer a continuidade do aprendizado na modalidade. Nos depoimentos coletados, procurou-se levantar dados sobre qual é o interesse dos jovens que vivem esta situação em seu cotidiano.

O projeto estudado trabalhou com a modalidade voleibol como eixo principal. Perguntados sobre como deve ser trabalhado o esporte no projeto social, encontrou-se:

"Eu creio que no projeto social, como o voleibol é o foco, acho que não tem muito como fugir daquilo. Porque quando as pessoas vão, por exemplo, quando eu fui, eu fui atrás do voleibol. Porque eu gostava de jogar e aí eu fui conhecendo outras coisas. Eu acho que o foco não deve ser perdido, mas também trabalhando outras coisas, mas o foco não deve ser perdido." (Aluno)

Zaluar ( 1994, p. 197) reforça a discussão sobre o problema da superficialidade nas ações, afirmando ter encontrado em núcleos de programas sociais, através do esporte, problemas com adolescentes que não encontravam continuidade no desenvolvimento da modalidade. Ignorou-se o desejo dos jovens e também as possibilidades de formação profissional como atletas ou profissões afins. "Ainda no esporte, a idéia de que para pobre qualquer coisa serve predominou."

Bento (1999) defende a necessidade de repensar a pedagogia que, para substituir o emprego do esporte como ferramenta ideológica, ou onde se privilegiava apenas os mais aptos excluindo-se todos os outros, implantou-se uma espécie de ética indolor, com afrouxamento dos vínculos a compromissos e deveres e tudo que implique trabalho, esforço, disciplina, sacrifício, afinco, persistência e suor.

Como parte deste processo de continuidade, e em busca por aprimoramento na modalidade, o grupo enfrentou o desafio de participar de dois campeonatos, um municipal, onde em sua maioria participavam equipes de escolas públicas, e outro regional, composta por equipes de clubes da grande São Paulo, apresentando um nível bem mais alto que o primeiro. Nos dois anos de participação, foram ao todo 24 derrotas e 2 vitórias.

Ao aceitarem este desafio, os jovens foram alertados de que iriam enfrentar equipes com estruturas diferenciadas, com maior número de treinos semanais, turmas formadas por seletivas, maior apoio voltado especificamente para o treinamento, bem ao contrário do grupo estudado, que possuía apenas dois treinos por 
semana, em uma quadra com dimensões menores que as oficiais, pouco material e com jovens dispostos, mas sem terem passado por qualquer tipo de seletiva que não fosse a vontade e disponibilidade para estarem no projeto.

Nas lembranças do professor, encontra-se sua posição com relação à competição:

"Contesta-se também o tratamento esportivo na área social alegando ser fonte de frustrações, visto que poucos conseguirão ser atletas profissionais, mesmo não sendo este o objetivo do programa. Ora, se afirmo aos alunos que todos serão atletas e viverão suas glórias como os mais conhecidos, reconheço que a frustração poderá ocorrer. No entanto, se a proposta for a de desafiá-los a desenvolverem-se, a jogar cada vez melhor, buscar sim a vitória e lidar positivamente com a derrota, então entendo a frustração como fenômeno natural e que pode impulsioná-los ao crescimento, ao prazer por evoluir através de seus esforços individuais e coletivos." (Professor)

Zaluar ( I 994, p. 70) colabora com a discussão, quando cita em sua pesquisa sobre projetos sociais e a prática esportiva competitiva:

Todas as crianças entrevistadas, depois de alguma hesitação diante da pergunta "o que é espírito esportivo?" disseram que haviam aprendido a perder "sem chorar" ou "sem desanimar" ou "sem revoltar" ou ainda "sem brigar". Mas nenhuma delas deixou de acrescentar que queria ganhar. Afinal esta é a finalidade do jogo. E o gosto pela medalha era generalizado: todos vibravam pela sua conquista, os colegas, os familiares, os vizinhos.

E, confirmando as intenções do professor, vários de seus alunos discursam sobre os aprendizados vivenciados com a participação nos campeonatos:

"Essa participação nossa no pré-olimpico (campeonato metropolitano). Foram quantos jogos? Só sei que o número de derrotas foi muito maior que o de derrotas. A gente só teve 2 vitórias. E aí eu pensando muito eu acho que se o nosso grupo tivesse ganhado muito mais que perdido seria um pouco mais dificil ser o grupo que foi. É claro que a vitória une, o grupo ficava feliz e motivado, enfim, mas eu via, todo final dos jogos, da perda dos jogos, eu via quanto o grupo ficava ainda mais forte. E o grupo não pensava assim, não o próximo a gente ganha, mas o grupo tentava encontrar um monte de estratégias para tentar melhorar pelo menos um pouco dentro de quadra." (Aluno)

"A gente continuou perdendo e sei lá, a gente continuou perdendo, mas eu penso que o que a gente conquistou com as nossas derrotas foi muito maior do que com as vitórias, assim. As vitórias ajudaram. Foram um gás, mas eu penso que as derrotas foram mais significativas." (Aluno)

Como exposto, o desejo por aprender uma modalidade profundamente, testando suas competências, se desafiando e desafiando a imagem de incapacidade que a própria sociedade formula sobre o jovem morador da "favela", é bastante presente nos discursos dos entrevistados, reforçando a importância deste aspecto. 
Ainda é possível retirar dos depoimentos, indicativos de que a continuidade no aprendizado do esporte proporcionou motivação e elevação da auto-estima, capazes de contribuir para a permanência da grande maioria dos jovens durante os três anos investigados de projeto.

\section{O VALOR DE SE FAZER PARTE!}

Foi percebido com grande ênfase no discurso dos jovens, um fenômeno também defendido por autores que tratam das ações em projetos socioeducativos, o sentimento de pertencimento. Segundo Gomes (2002, p. 102):

[...] o ser humano, para manter sua saúde mental, precisa se sentir "em casa", ou seja, pertencer a algo - ser reconhecido e reconhecer, ser identificado e identificar seus pares - e ter certa relação de ser parte de um todo maior, que o colhe e o protege. Pertencer a algo, além de nos descentrar de uma onipotência egocêntrica, acalenta um sentimento de prazer, de comunhão, já que o ser humano não pode responder sozinho pelas suas questões existenciais.

Ao se propor uma diversidade de estímulos que oferecem desafios, que exijam ações em conjunto, superação, apoio, cobrança mútua, os quais o esporte é capaz de estimular, é possível que se desenvolva este sentimento de pertencimento, de identidade de grupo. Encontrou-se também em Castro, Abramovay e Rua (200 I, p. 492) a importância deste sentimento:

Sentimento de "pertence" é um construto valorizado no universo cognitivo das entidades e também o debate sobre o protagonismo juvenil. A idéia é estimular os jovens para que remodelem referências e valores, identificando-se com as práticas, princípios e produtos dos projetos, situando-se como parte deles, em um momento, e como parte de uma comunidade com responsabilidades sociais, em outro.

Nas falas de diversos personagens da comunidade, a imagem do grupo unido e que fortalece a individualidade está bastante presente. Fazer parte de uma equipe que assume responsabilidades diversas no projeto e é reconhecida positivamente, parecem significar valores importantes para auxiliar na formação dos jovens.

Os desafios da montagem da equipe e da participação em campeonatos foram componentes para a união do grupo:

"Eu gostava bastante dos campeonatos, porque eu acho que os campeonatos juntava muito o time feminino, o time feminino era muito afastado, por intrigas... Então, eu acho que a quando a gente se juntava mesmo para jogar a gente se unia. A gente esquecia as diferenças, não é? Então a gente se apegava, via que aquele abraço que a gente tava dando era uma abraço 
verdadeiro, não aquele abraço que você dá, "Hã, oi!..."(fisionomia de desagrado) , sem graça, era um abraço que tinha algo a ver com o grupo." (Aluno)

"Porque quando eu estava lá dentro eu jogava, eu jogava com garra, eu jogava para quê? Para quando eu chegar no campeonato, a nossa equipe, o nosso time mostrar que e gente era forte, mostrar que a gente era unida, aí eu gostava de estar lá por isso." (Aluno)

O círculo de amizade formado pelo grupo é destacado por seus integrantes:

"Outro ponto que ficou muito forte e isto é até hoje assim, o quanto todos nós, o grupo que se formou, de 40, hoje eu digo que são 20, ele é muito forte. E já passou o quê? Já passou 2 anos que a gente não está mais no projeto, não está mais envolvido com as atividades, mas independentemente de tudo isso a gente ainda está junto, a gente ainda está unido, a gente pensa em estratégias para estar junto um do outro." (Aluno)

"Com relação ao time, nós fechamos um grupo muito legal, até mesmo depois do treino nós nos reuníamos, a gente conversava fora tanto de voleibol como de diversos assuntos, a gente tinha aquele laço de amizade. Na hora da dificuldade procurar saber, montar uma estratégia para sobressair da dificuldade. Acho que este laço de amizade que acabou ficando, de conversar, durou muito tempo. No outro dia a gente se reunia para conversar, discutir sobre voleibol, acho que este é um ponto legal." (Aluno)

Agir em grupo é aumentar as possibilidades de atuação, principalmente na comunidade de Heliópolis, como afirma a liderança entrevistada:

"Têm jovens que na mudança enquanto pessoa, de se cuidar, também isto teve. Ele se tornou mais questionador, mais amigo do outro. Eles se fortaleceram enquanto grupo. Eu acho que isso foi bacana, eles traziam coisas enquanto grupo. Não falavam no individual. E para esta comunidade acho que é isto que é importante, não é? Porque se você começa a trabalhar no individual, você se perde, e eles vieram com uma força enquanto o grupo." (Liderança)

O sentimento de pertencimento e suas características, como os laços de amizade, a busca por objetivos comuns, as responsabilidades assumidas, o apoio, a cooperação entre os jovens, a aquisição de maior força de representação na comunidade e a permanência de algumas destas relações, indicam que o fato de pertencer ao grupo foi relevante no processo vivenciado.

\section{O PROFESSOR ME CONHECE E ME CONSIDERA! A RELAÇÃO PROFESSOR E ALUNO.}

As características de um professor e sua relação com o aluno também foi tema constante nos depoimentos dos entrevistados. Qual o perfil ideal para o professor 
em um projeto socioeducativo? Como deve ser sua relação com seu aluno? Para contribuir com as possíveis respostas, Abib (2006, p. 90) ilustra a importância dada a esta relação quando discute o ensino não-formal da capoeira por velhos mestres:

Segundo o mestre Moraes, em seu depoimento, o toque, na "pedagogia do africano", é fundamental. "Ele toca o aluno para passar o sentimento... ele não toca unicamente para consertar o movimento... ele passa muito mais a vontade de ver o aluno aprendendo, do que ensinar o movimento correto". Essa forma tradicional de ensinar passa pela proximidade que deve existir entre mestre e o aprendiz. Uma proximidade corporal em que o afeto, a atenção e a disponibilidade do mestre mostram-se integralmente.

Em concordância à citação anterior, encontrou-se nos depoimentos a necessidade do professor se aproximar de seu aluno, construindo uma relação de confiança e amizade, conhecendo a comunidade na qual vai trabalhar:

"Além de dar a aula ele tem que conhecer os alunos, os moradores, muitas vezes o tráfico, e dependendo da realidade, isto é importante, ele tem que conhecer o contexto em que ele está inserido, ele tem que fazer parte do contexto, ele tem que, na verdade, viver no contexto." (Professor)

"Tem a questão da amizade, de você conhecer seu aluno, se preocupar com ele, e eu acho que quando a gente conhece realmente o aluno, sua realidade, quando a gente dá a oportunidade para ele falar simplesmente da vida dele, eu vejo que o aluno se sente confiante, o aluno fala: caramba, nele eu posso confiar!" (Professor)

Outra característica atribuída ao professor ideal faz referência à vocação, ao gostar do que faz, se deixar envolver pela causa do projeto. Segundo relatos, assim ele terá maiores chances de provocar mudanças reais na comunidade:

"Olha, tem que gostar mesmo, viu! Gostar daquilo que faz. Acho que é importante em qualquer profissão, tem que gostar mesmo, se sentir parte daquilo que o manda chuva está te falando. Se sentir parte e amar, eu acho que é o principal. É você amar aquilo que você está fazendo. Só a chance deste Professor poder...vai trabalhar com crianças, não é? Com todas as faixas de idade, e pode trazer muitos benefícios para estas crianças. Eu acho que o principal é ter que gostar mesmo." (Aluno)

"Ele tem que gostar de estar ensinando, gostar do que ele está fazendo." (Aluno)

Como visto anteriormente, espera-se que o projeto esportivo tenha continuidade e profundidade. Portanto, também é desejado que o profissional tenha uma boa formação na modalidade: 
"Primeiro o Professor tem que manjar muito do esporte que ele está trabalhando. Por exemplo, se você está no voleibol, você tem que entender do voleibol." (Professor)

"É lógico, importante conhecer do que a pessoa esta falando. Não vai falar de voleibol e chegar lá falando de chuchu! Tem que ter uma base, uma formação legal." (Aluno)

Segundo Araújo (2002), um elemento muito importante na relação de ensino é a admiração dos alunos por seu professor. Ela é proveniente do sentimento de respeito, que pode ser alcançado pelo temor à punição ou pela reciprocidade afetiva (respeito mútuo). $\bigcirc$ autor acredita que a admiração gerada pelo respeito mútuo é a que pode garantir harmonia nas relações interpessoais em ambiente educacional. Tal afetividade mencionada nada tem a ver com as atitudes superficiais de "falso" carinho, e sim com ações refletidas e em concordância com a individualidade e ambiente em que os alunos estão envolvidos.

A figura do professor, como um exemplo a ser admirado, é também evidenciado e descrito pelos jovens, e afirmado como de grande importância no cotidiano do projeto:

"Acho que se for um projeto social, tem que ter uma preocupação em formar pessoas, em ser exemplo, é inevitável, os alunos vão olhar para esta pessoa e vão dizer: 'puxa, quando eu crescer eu quero ser assim, eu quero fazer isso!', então de qualquer forma ele tem que ter consciência de que ele vai ser um modelo, então ele tem que ter um comportamento que de certa forma seja exemplar." (Aluno)

Além do exemplo, muitos entrevistados fizeram referência à relação de proximidade e amizade do professor com os alunos. Não basta conhecer a comunidade, ter uma conduta correta, cumprir com as obrigações. Exige-se maior envolvimento:

"O Professor também tem que, isto acontece muito, eu tenho visto, se o Professor vem para uma comunidade, e ele vem apenas para dar aula, a aula dele, não que isto seja um pecado, mas eu acho que isto não serve. Porque o Professor tem que querer transformar, ele tem que querer fazer parte desta transformação também, Ele tem que ter este desejo de, aquelas crianças que ele tiver na mão, dele tentar fazer com que aquelas crianças se tornem pessoas que queiram transformar a comunidade. Porque a gente vê muito Professor que não é da comunidade que vem trabalhar no projeto social, mas que você não vê isto nele." (Professor)

"Primeira coisa ele tem que ter aquela coisa, eu não sei dizer o nome, sabe aquela coisa para cativar os alunos, além de ser o Professor, ser amigo também. Primeiro de tudo ele tem que ser amigo dos seus alunos depois vem o Professor." (Aluno) 
As referências extraídas nos depoimentos deixam clara a importância fundamental do professor na dinâmica do projeto. O conhecimento técnico da área a ser trabalhada deve estar atrelado à relação afetiva do professor com seus alunos e à vocação para a ação social. Enfim, as vozes da comunidade indicam a necessidade de um profissional que conheça, se envolva e se comprometa com seus moradores.

\section{CONSIDERAÇÕES FINAIS}

Oferecer esporte às crianças carentes para tirá-las da rua é uma conhecida afirmação utilizada em diversos projetos sociais. De fato, foi observado que as ruas representavam riscos para os jovens, principalmente por causa da violência e do tráfico. Mas, ao tirá-los deste ambiente, é necessário refletir sobre o que irá ser oferecido e, principalmente, como será oferecido, para que estes estímulos sejam ricos, proporcionem aprendizados reais e sejam capazes de mantê-los motivados a continuar no projeto durante sua idade limite.

A ideia de oferecer o esporte como ação recreativa pode ser eficiente no primeiro momento, mas é possível concluir que é necessário oferecer continuidade no processo de aprendizado da modalidade. Permanecer com objetivos recreativos pode significar falta de compromisso dos alunos, pois, como afirma uma das jovens, para brincar pode-se fazê-lo na rua.

Proporcionar continuidade no desenvolvimento do esporte não significa que acontecerá a exclusão, desde que se ofereça espaço para todos, respeitando seus limites de evolução. Equipes ou grupos de diferentes níveis pode ser uma solução para a tão discutida exclusão.

É possível afirmar que a exclusão também ocorre, ao não se oferecer a oportunidade aos jovens de se desenvolverem no esporte. Qual pai ou professor, ao perceber que o filho ou aluno se interessa por um conhecimento, deseja se aprofundar, melhorar, não o incentivará? Por que com crianças carentes, em projetos sociais, o cenário se apresenta diferente? De acordo com os depoimentos apresentados, propõe-se que através da busca contínua por desenvolvimento, ofereça-se aos jovens moradores de classes populares, estímulos e sentimentos pouco vividos por eles, como a valorização por seu trabalho, persistência em melhorar, sentimento de pertencimento a um grupo, com objetivos em comum, enfrentamento e superação das frustrações, elevação da auto-estima:

"Para mim foi super importante porque foi uma maneira de dizer, de mostrar para a gente que por mais que a gente viva dentro de uma sociedade, que ela tem esta visão negativa: 'É favelado, é coitado, vamos dar coisas de graça para eles, porque eles não têm capacidade!', acredito que a gente conseguiu mostrar que a gente tinha capacidade." (Aluno) 
Ao se refletir sobre uma temática tão complexa, não é possível deixar de considerar as relações interpessoais do grupo e de todos os seus envolvidos. $\bigcirc$ sentimento de pertencimento deste grupo é de fundamental importância. Como colocado anteriormente, o conjunto é capaz de fortalecer o indivíduo, a ponto de melhorar seu relacionamento consigo mesmo e com sua comunidade.

Caminhando contra a ação das "más influências" (expressão popular que sugere a relação com "falsos amigos", que conduzem para o caminho da delinquência), os vínculos de amizade podem exercer grande apoio na formação dos jovens. Espera-se que, se estes estiverem envolvidos em movimentos de superação, desenvolvimento, aprendizado com significados em suas vidas, a influência positiva na busca pelo crescimento pode ser potencializada.

A figura do professor também deve estar inserida nesta teia de relações, como uma referência que exerce grande influência, representando muitas vezes o exemplo a ser seguido. Este profissional deve, segundo a comunidade, conhecer seus alunos, sua realidade, estar compromissado com a missão do projeto e ser profundo conhecedor do eixo pelo qual irá atuar.

Colaborando para a conclusão deste texto, Freire (2003) defende que se ensine o esporte a todos, que se ensine bem a todos, que se ensine mais que do esporte a todos, e finalmente que se ensine a gostar do esporte.

Acredita-se que ensinar bem o esporte é ensinar mais que ele mesmo. É explorá-lo ao nível de exercer tal fascínio nos jovens, que ele represente um contraponto tão forte quanto as pressões da violência generalizada que sofrem todos os dias. É necessário que se planeje e encare o esporte em projetos sociais como uma ação que seja tão profunda quanto as marcas da exclusão que estas pessoas vivem. Acredita-se, por fim, que se não for desta maneira, a pedagogia do esporte não será páreo para a pedagogia das ruas e do tráfico!

Something besides to take away of the street: teaching sport in a socialeducational project

ABSTRACT: The present article is related to a research based on ethnography and memory reconstruction guided by oral history. Its main purpose is to reveal relevant characteristics about a social and educational project implemented in Heliópolis community, in the city of São Paulo, seeking to understand the changes experienced by adolescents in their everyday life, relating the possible contributions for structuring actions which use sport as the guideline. The results underscored as most significant are the relationship between teacher and student, the feeling of belonging and the continuity of learning. The study is concluded by indicating the importance of careful pedagogic treatment when offering sports as the focus of action towards a community.

KEYWORDS: pedagogy of the sport; project social education, popular-classes; teenagers. 
Algo para más allá de sacar de la calle: la enseñanza del deporte en proyecto social y educativo

RESUMEN: El presente artículo está relacionado a una investigación etnográfica y de reconstrucción de memórias a través de la historia oral. El objetivo principal del trabajo es presentar características relevantes de un proyecto social y educativo en la comunidad de Heliópolis, en la ciudad de São Paulo, tratando de comprender las transformaciones experimentadas por los adolescentes en su rutina, referiendo las possibles contribuiciones a la formación de acciones que toman el deporte como influenciador. Se destacaran como resultados más significativos la relación professor-estudiante, el sentimiento de pertenencia y la continuidad en el aprendizaje. Se concluyó el estudio con la revelación de la importância de un cuidadoso tratamiento pedagógico en el ofrecimiento de actividades deportivas como foco de acciónes orientadas a las comunidades populares.

PALABRAS CLAVE: pedagogía del deporte, proyecto socioeducativo, clases populares; adolescentes.

\section{REFERÊNCIAS}

ABIB, P. R. J. Os velhos capoeiras ensinam pegando na mão. Cadernos CEDES, Campinas, v. 26, n. 68, p. 86-98, jan./abr. 2006.

ANDRÉ, M. E. D. A. Etnografia da prática escolar. Campinas: Papirus, 1995.

ARAÚJO, U. F. A construção de escolas democráticas: histórias sobre complexidade, mudanças e resistências. São Paulo: Moderna, 2002.

BENTO, J. O. Desporto: discurso e substância. São Paulo: Campo das Letras; Porto: Universidade do Porto, 1999.

BRAGA, E. S. A constituição social da memória: uma perspectiva histórico cultural. ljuí: Ed. da Unijuí, 2000.

CASTRO, M. G.; ABRAMOVAY, M.; RUA, M. G. Cultivando vidas, desarmando violências: experiências em educação, cultura, lazer, esporte e cidadania com jovens em situações de pobreza. Brasilia: UNESCO, 2001.

FERNANDES, R. C. O que é o terceiro setor? In: IOSCHPE, E. Terceiro setor: desenvolvimento social sustentado. Rio de Janeiro: Paz e Terra, 2005. p. 25-33.

FREIRE, J. B. Pedagogia do futebol. Campinas: Autores Associados, 2003.

GEERTZ, C. A interpretação das culturas. Rio de Janeiro: Guanabara Koogan, 1989.

GOHN, M. G. Educação não-formal e cultura política. São Paulo: Cortez, 200 I .

GOMES, C. M. A. Feuerstein e a construção mediada do conhecimento. Porto Alegre: Artmed, 2002. 
HIRAMA, L. K. Algo para além de tirar as crianças da rua: a pedagogia do esporte e projetos socioeducativos. 2008. 359 f. Dissertação (Mestrado em Educação Física) - Faculdade de Educação Física, Universidade Estadual de Campinas, Campinas, 2008.

.; MONTAGNER, P. C. Algo para além de tirar as crianças da rua: a pedagogia do esporte e projetos socioeducativos. São Paulo: Phorte. No prelo.

INSTITUTO BRASILEIRO DE GEOGRAFIA E ESTATÍSTICA (IBGE). As fundações privadas e associações sem fins lucrativos no Brasil: 2002. Rio de Janeiro, 2004.

LAPLANTINE, F. Aprender antropologia. São Paulo: Brasiliense, 1988.

REDE GLOBO DE TELEVISÃO. Jogos Panamericanos 2007. Disponível em: <www.globo. com/rjtv>. Acesso em: 24 jul. 2007.

THOMPSON, A. A. Do compromisso à eficiência? Os caminhos do terceiro setor na América Latina. In: IOSCHPE, E. $3^{\circ}$ setor: desenvolvimento social sustentado. Rio de Janeiro: Paz e Terra, 2005. p. $4 \mathrm{I}-48$.

UNIÃO DOS NÚCLEOS, ASSOCIAÇÕES E SOCIEDADES DOS MORADORES DE HELIÓPOLIS E SÃO JOÃO CLIMACO (UNAS). Apresenta informações sobre a comunidade de Heliópolis. Disponível em: <http://www.unas.org.br>. Acesso em: 17 ago. 2007.

VON SIMSON, O. M. Memória, cultura e poder na sociedade do esquecimento. Revista Acadêmica das Faculdades Integradas Campos Salles, São Paulo, n. 6, p. I4-32, maio 2003. ZALUAR, A. Cidadãos não vão ao paraíso: juventude e política social. Campinas: Ed. da Unicamp, 1994.

Recebido: 31 ago 2010 Aprovado: 19 jan 2011

Endereço para correspondência: Leopoldo Katsuki Hirama Universidade Federal do Recôncavo da Bahia Caixa postal 23, Amargosa, Bahia, Brasil CEP 45300-000 